\title{
Study on Cross Cultural Communication in Global Citizen Age
}

\author{
Qinglan Lei ${ }^{1, a}$ \\ ${ }^{1}$ Guizhou University of Finance and Economics, Guiyang 550003, Guizhou ,China \\ a QinglanLei@163.com
}

Keywords: Cross culture, Communication, Global age

\begin{abstract}
As the whole world is being interconnected in this global citizen age, cross cultural communication is also discussed by people more frequently since cross cultural communication is closely related with various aspects such as daily life, work and international communications. Thus, this passage is to depict an image of cross cultural communication via several facets.
\end{abstract}

\section{Introduction.}

All communication is cultural -- it draws on ways we have learned to speak and give nonverbal messages. We do not always communicate the same way from day to day since factors like context, individual personality and mood interact with the variety of cultural influences we have internalized that influence our choices. Communication is interactive, so an important influence on its effectiveness is our relationship with others. Do they hear and understand what we are trying to say? Are they listening well? Do their responses show that they understand the words and the meanings behind the words we have chosen? Is the mood positive and receptive? Is there trust between them and us? Are there differences that relate to ineffective communication? The answers to these questions will give us some clues about the effectiveness of our communication and the ease with which we may be able to move through conflict.

\section{Time and space.}

Time is one of the most central differences that separate cultures and cultural ways of doing things. In the West, time tends to be seen as quantitative, measured in units that reflect the march of progress. It is logical, sequential, and present-focused, moving with incremental certainty toward a future the ego cannot touch and a past that is not a part of now. Novinger calls the United States a "chronocracy," in which there is such reverence for efficiency and the success of economic endeavors that the expression "time is money" is frequently heard. This approach to time is called monochronic -- it is an approach that favors linear structure and focus on one event or interaction at a time. Robert's Rules of Order, observed in many Western meetings, enforce a monochronic idea of time. In the East, time feels like it has unlimited continuity, an unraveling rather than a strict boundary. Birth and death are not such absolute ends since the universe continues and humans, though changing form, continue as part of it. People may attend to many things happening at once in this approach to time, called polychronous. This may mean many conversations in a moment (such as a meeting in which people speak simultaneously, "talking over" each other as they discuss their subjects), or many times and peoples during one process (such as a ceremony in which those family members who have died are felt to be present as well as those yet to be born into the family).

A good place to look to understand the Eastern idea of time is India. There, time is seen as moving endlessly through various cycles, becoming and vanishing. Time stretches far beyond the human ego or lifetime. There is a certain timeless quality to time, an aesthetic almost too intricate and vast for the human mind to comprehend. Consider this description of an aeon, the unit of time which elapses between the origin and destruction of a world system: "Suppose there is a mountain, of very hard rock, much bigger than the Himalayas; and suppose that a man, with a piece of the very finest cloth of Benares, once every century should touch that mountain ever so slightly -- then the time it would take him to wear away the entire mountain would be about the time of an Aeon."

Differences over time can play out in painful and dramatic ways in negotiation or conflict-resolution processes. An example of differences over time comes from a negotiation 
process related to a land claim that took place in Canada. First Nations people met with representatives from local, regional, and national governments to introduce themselves and begin their work. During this first meeting, First Nations people took time to tell the stories of their people and their relationships to the land over the past seven generations. They spoke of the spirit of the land, the kinds of things their people have traditionally done on the land, and their sacred connection to it. They spoke in circular ways, weaving themes, feelings, ideas, and experiences together as they remembered seven generations into the past and projected seven generations forward. It is also true that cultural approaches to time or communication are not always applied in good faith, but may serve a variety of motives. Asserting power, superiority, advantage, or control over the course of the negotiations may be a motive wrapped up in certain cultural behaviors (for example, the government representatives' detailed emphasis on ratification procedures may have conveyed an implicit message of control, or the First Nations' attention to the past may have emphasized the advantages of being aware of history). Culture and cultural beliefs may be used as a tactic by negotiators; for this reason, it is important that parties be involved in collaborative-process design when addressing intractable conflicts. As people from different cultural backgrounds work together to design a process to address the issues that divide them, they can ask questions about cultural preferences about time and space and how these may affect a negotiation or conflict-resolution process, and thus inoculate against the use of culture as a tactic or an instrument to advance power.

Any one example will show us only a glimpse of approaches to time as a confounding variable across cultures. In fact, ideas of time have a great deal of complexity buried within them. Western concepts of time as a straight line emanating from no one in particular obscure the idea that there are purposive forces at work in time, a common idea in indigenous and Eastern ways of thought. From an Eastern or indigenous perspective, Spirit operates within space and time, so time is alive with purpose and specific meanings may be discerned from events. A party to a negotiation who subscribes to this idea of time may also have ideas about fate, destiny, and the importance of uncovering "right relationship" and "right action." If time is a circle, an unraveling ball of twine, a spiral, an unfolding of stories already written, or a play in which much of the set is invisible, then relationships and meanings can be uncovered to inform current actions. Time, in this polychronic perspective, is connected to other peoples as well as periods of history.

\section{Fate and personal responsibility.}

Another important variable affecting communication across cultures is fate and personal responsibility. This refers to the degree to which we feel ourselves the masters of our lives, versus the degree to which we see ourselves as subject to things outside our control. Another way to look at this is to ask how much we see ourselves able to change and maneuver, to choose the course of our lives and relationships. Some have drawn a parallel between the emphasis on personal responsibility in North American settings and the landscape itself. The North American landscape is vast, with large spaces of unpopulated territory. The frontier mentality of "conquering" the wilderness, and the expansiveness of the land stretching huge distances, may relate to generally high levels of confidence in the ability to shape and choose our destinies.

In this expansive landscape, many children grow up with an epic sense of life, where ideas are big, and hope springs eternal. When they experience setbacks, they are encouraged to redouble their efforts, to "try, try again." Action, efficacy, and achievement are emphasized and expected. Free will is enshrined in laws and enforced by courts.

Now consider places in the world with much smaller territory, whose history reflects repeated conquest and harsh struggles: Northern Ireland, Mexico, Israel, Palestine. In these places, there is more emphasis on destiny's role in human life. In Mexico, there is a legacy of poverty, invasion, and territorial mutilation. Mexicans are more likely to see struggles as inevitable or unavoidable. Their fatalistic attitude is expressed in their way of responding to failure or accident by saying "ni modo" ("no way" or "tough luck"), meaning that the setback was destined.

This variable is important to understanding cultural conflict. If someone invested in free will 
crosses paths with someone more fatalistic in orientation, miscommunication is likely. The first person may expect action and accountability. Failing to see it, they may conclude that the second is lazy, obstructionist, or dishonest. The second person will expect respect for the natural order of things. Failing to see it, they may conclude that the first is coercive or irreverent, inflated in his ideas of what can be accomplished or changed.

\section{Face and face-saving.}

Another important cultural variable relates to face and face-saving. Face is important across cultures, yet the dynamics of face and face-saving play out differently. Face is defined in many different ways in the cross-cultural communication literature. Novinger says it is "the value or standing a person has in the eyes of others...and that it relates to pride or self-respect.". Others have defined it as "the negotiated public image, mutually granted each other by participants in communication."

The starting points of individualism and communitarianism are closely related to face. If I see myself as a self-determining individual, then face has to do with preserving my image with others and myself. I can and should exert control in situations to achieve this goal. I may do this by taking a competitive stance in negotiations or confronting someone who I perceive to have wronged me. I may be comfortable in a mediation where the other party and I meet face to face and frankly discuss our differences. If I see my primary identification as a group member, then considerations about face involve my group. Direct confrontation or problem-solving with others may reflect poorly on my group, or disturb overall community harmony. I may prefer to avoid criticism of others, even when the disappointment I have concealed may come out in other, more damaging ways later. When there is conflict that cannot be avoided, I may prefer a third party who acts as a shuttle between me and the other people involved in the conflict. Since no direct confrontation takes place, face is preserved and potential damage to the relationships or networks of relationships is minimized.

\section{Nonverbal communication.}

Nonverbal communication is hugely important in any interaction with others; its importance is multiplied across cultures. This is because we tend to look for nonverbal cues when verbal messages are unclear or ambiguous, as they are more likely to be across cultures (especially when different languages are being used). Since nonverbal behavior arises from our cultural common sense -- our ideas about what is appropriate, normal, and effective as communication in relationships -- we use different systems of understanding gestures, posture, silence, spacial relations, emotional expression, touch, physical appearance, and other nonverbal cues. Cultures also attribute different degrees of importance to verbal and nonverbal behavior.

Differences of interpretation may lead to conflict, or escalate existing conflict. Suppose a Japanese person is explaining her absence from negotiations due to a death in her family. She may do so with a smile, based on her cultural belief that it is not appropriate to inflict the pain of grief on others. For a Westerner who understands smiles to mean friendliness and happiness, this smile may seem incongruous and even cold, under the circumstances. Even though some facial expressions may be similar across cultures, their interpretations remain culture-specific. It is important to understand something about cultural starting-points and values in order to interpret emotions expressed in cross-cultural interactions.

Finally, line-waiting behavior and behavior in group settings like grocery stores or government offices is culturally-influenced. Novinger reports that the English and U.S. Americans are serious about standing in lines, in accordance with their beliefs in democracy and the principle of "first come, first served."The French, on the other hand, have a practice of line jumping that irritates many British and U.S. Americans. In another example, immigrants from Armenia report that it is difficult to adjust to a system of waiting in line, when their home context permitted one member of a family to save spots for several others.

These examples of differences related to nonverbal communication are only the tip of the iceberg. Careful and cultivating relationships across cultures will all help develop the cultural fluency to 
work effectively with nonverbal communication differences.

\section{Summary.}

Cross-cultural communication is a field of study that looks at how people from different cultural backgrounds communicate, in similar and different ways among themselves, and how they endeavor to communicate across cultures. Cultures differ from country to country. It is essential to carefully research cultures from different countries or regions so as to effectively avoid some unnecessary conflicts.

\section{References}

[1] HuWenzhong, Cultural Custom Comparison[M], Foreign Language Teaching and Researching Press, 1999.

[2] LinYutang, Art of Life[M], Foreign Language Teaching and Researching Press, 1998.

[3] Sam, Cross Cultural Communication[M], Sanlian Bookstore, 1998.

[4] DuoXiaoping, Study on Chinese and Western Culture From the Perspective of Diet[J], Lanzhou Industrial Higher Vocational School Paper, 2005(12).

[5] LiMingying, Social Custom and Diet Culture[J], Jinzhou Normal College Newspaper, 1997(3). 